\title{
Development of Novel As-Cast Ti-Mo-Zr Alloys for Biomedical Applications
}

\author{
Israel Ramos Rodrigues ${ }^{a, b}$ (D), Renan Eduardo de Lima Lopes ${ }^{a, b}$ (D), Carlos Roberto Grandini ${ }^{a, b} *$ (D) \\ ${ }^{a}$ Universidade Estadual Paulista (UNESP), Laboratório de Anelasticidade e Biomateriais, 17.033-360, \\ Bauru, SP, Brasil. \\ ${ }^{b}$ Institute of Biomaterials Tribocorrosion and Nanomedicine -Brazilian Branch (IBTN), 17.033-360, \\ Bauru, SP, Brasil.
}

Received: September 28, 2021; Accepted: October 20, 2021.

\begin{abstract}
Titanium is one of the most utilized metals for orthopedic implants. This element has excellent mechanical and biological properties. As a strategy to develop a new system of alloys that do not cause health problems to the patient, such as the Ti-6Al-4V alloy, a new group of alloys has been designed to meet these expectations. Molybdenum, when associated with titanium, reduces the transition temperature from $\alpha$ to the $\beta$ phase. Zirconium increases the corrosion resistance, decreases the melting point, and improves the alloy's biocompatibility. The alloys with the beta phase's predominance are the most desirable for biomedical applications due to their higher mechanical compatibility with the bone tissue. This paper presents the preparation of as-cast Ti-10Mo-xZr ( $\mathrm{x}=30,40$, and $50 \mathrm{wt} \%)$ alloys and their characterization by measurements of density, energy dispersive spectrometry (EDS), $\mathrm{x}$-ray diffraction, optical and scanning electron microscope (SEM). The density values were higher than that of pure titanium due to the zirconium and molybdenum. The EDS measurements reveal a suitable stoichiometry of the elements and no impurities contamination. In the x-ray diffraction and microscopy measurements, it was observed only peaks of the beta phase. This new system of Ti-alloys is promising for biomedical applications.
\end{abstract}

Keywords: Ti-Alloys, $\beta$-phase alloys, Microstructure.

\section{Introduction}

Titanium alloys have a high range of mechanical, physical, and corrosion resistance properties, which arouse an extreme interest in the aerospace, energetic, chemical, and health industries ${ }^{1}$. Those alloys have some attributes and properties, either with high hardness, low elasticity modulus, or high melting point. Biomaterials play an important role in human development today. They can be divided into four major classes: metals and their alloys, polymers, ceramics, and natural materials ${ }^{2}$.

Concerning health applications, the first alloys used were $\alpha$-type alloys, such as commercially pure titanium and alloys developed for the aeronautical industry ${ }^{3}$. Then, the $\alpha+\beta$ type alloys gained attention, due to their wide range of properties, with the Ti-6Al-4V alloy being widely used today ${ }^{4,5}$. However, there have been reports that aluminum and vanadium ions released into the bloodstream could cause cytotoxic effects and neurological problems (such as Alzheimer's disease) $)^{6,7}$. This new class of titanium alloys has been looking for $\beta$-type alloys, as they have lower elasticity modulus, among all classes of titanium alloys ${ }^{8,9}$. Such alloys have been produced with the addition mainly of molybdenum $^{10,11}$, zirconium ${ }^{12-15}$, tantalum ${ }^{16,17}$, and niobium ${ }^{18-21}$, which are elements that do not present cytotoxic reactions with the organism.

The $\beta$ metastable alloys consist of the predominance of the $\beta$-phase. However, it is still possible to contain small

*e-mail: carlos.r.grandini@unesp.br fractions of the $\omega$ phase due to the thermomechanical processes derived from the production of this material. These alloys are used in structural applications where high strain resistance, stiffness, corrosion resistance, and low modulus of elasticity are required. These characteristics transform the metastable $\beta$ alloys attractive to engineering and medicine, even considering their high production cost, as these materials also present excellent biocompatibility for the use of implants and interactions with bone tissue ${ }^{22}$.

Titanium in its entirety manages to change its crystalline structure in some temperature fields. Allotropic transformation is called a complete transformation from one crystalline structure to another, and when this phenomenon occurs, its transformation temperature is called the transition temperature ${ }^{23}$. Pure titanium has a compact $\alpha$-phase hexagonal structure at low temperatures. For values higher than the $882^{\circ} \mathrm{C}$ transition temperature, this assumes a cubic body structure centered with phase $\beta^{24}$. Earlier studies state that the elasticity modulus for $\beta$-phase alloys is less than alpha-phase alloys ${ }^{1}$. Molybdenum is a strong $\beta$-stabilizer and can have a wide range of compositions where the $\alpha$ and $\beta$ phases of titanium can be present ${ }^{25}$. The Ti-Mo system is a set of alloys widely studied because of their excellent mechanical properties, corrosion resistance, and low modulus of elasticity ${ }^{10,26-28}$. Thus, for the alloy to present and stabilize characteristics referring to the beta phase, a minimum of $10 \%$ by weight of molybdenum is necessary ${ }^{28,29}$. 
Zirconium is an element that belongs to the same group as titanium in the periodic table, presenting similar chemical properties $^{30}$. Zirconium acts as a strong hardening agent for the solid solution ${ }^{31}$. This element is easy to form solid solutions with titanium, which is added to improve mechanical and corrosion resistance and improve biocompatibility ${ }^{32}$. Adding zirconium can also decrease the martensitic transformation temperature (Ms) of the $\alpha^{\prime}$ phase and slightly decrease the alloy's melting temperature ${ }^{14,15}$. The Ti-Zr system has advantageous characteristics concerning its mechanical and biological properties, such as a higher tensile strength than commercially pure titanium, good biocompatibility, and higher elastic recovery. This factor provides this system high demand for dental applications ${ }^{33}$.

In this context, this paper's purpose was to prepare and characterize a novel set of titanium alloys containing molybdenum and zirconium, aiming at biomedical applications. The alloys were obtained by arc-melting and characterized chemical, structural, and microstructurally to better understand this beta-type alloy's properties.

\section{Materials and Methods}

The alloys were prepared using the precursor elements of high purity, such as titanium (grade 2) in bars, zirconium in wire $(98.5 \%$ purity), and molybdenum in wire ( $99.0 \%$ purity) in their proper proportions. The precursors were melted in an arc-fusion furnace, with a controlled argon atmosphere to prevent contamination, in a water-cooled copper crucible and the non-consumable tungsten electrode. The ingots were re-melted five times to ensure homogeneity. The ingots were cooled naturally into the furnace.

A chemical semi-quantitative microanalysis was performed using dispersive energy spectroscopy (EDS) in an OXFORD detector, model INCA X-Act, coupled to the scanning electron microscope EVO LS15 by Carl Zeiss. Alloy elements were mapped to assess the material's distribution and homogeneity.

The density of the alloys was obtained by Archimedes principle, using an Explorer model Ohaus analytical balance.

The alloys' structure was obtained by X-ray diffraction measurements performed on a Rigaku diffractometer model $\mathrm{D} / \mathrm{Max} 2100$ / PC, with $\mathrm{Cu}-\mathrm{K} \alpha(\lambda=1.5406 \AA)$ radiation. The data will be collected using the powder method and fixed time mode, with a step of $0.02^{\circ}$ ranging from $10^{\circ}$ to $100^{\circ}$, and a collection time of $3.2 \mathrm{~s}$.

Microstructural characterization was performed using an optical microscope Olympus BX51M model. Scanning electron microscopy images were obtained using an electron microscope Carl Zeiss EVO LS15 model. These microscopic techniques were used to observe the current phases and their distributions, the structure's quality, and the grains' size.

\section{Results and Discussion}

Figure 1 shows the energy peaks related to the composition of the alloy using the EDS technique. Through this technique, it was possible to obtain the chemical microanalysis of the produced alloys. Analyzing Figure 1 shows that it is possible to identify energy peaks related to the elements that compose the alloy: titanium, molybdenum, and zirconium. Table 1 shows the quantitative chemical analysis of the produced alloy using EDS. The data contained in Table 1 indicate a good melting of the system, where there is only a slight deviation concerning the composition of the alloys respecting the proposed stoichiometry. The ASTM F2066-13 standard $^{34}$ (which standardizes the Ti-15Mo alloy) states that the concentration of the elements must be $\pm 1 \mathrm{wt} \%$
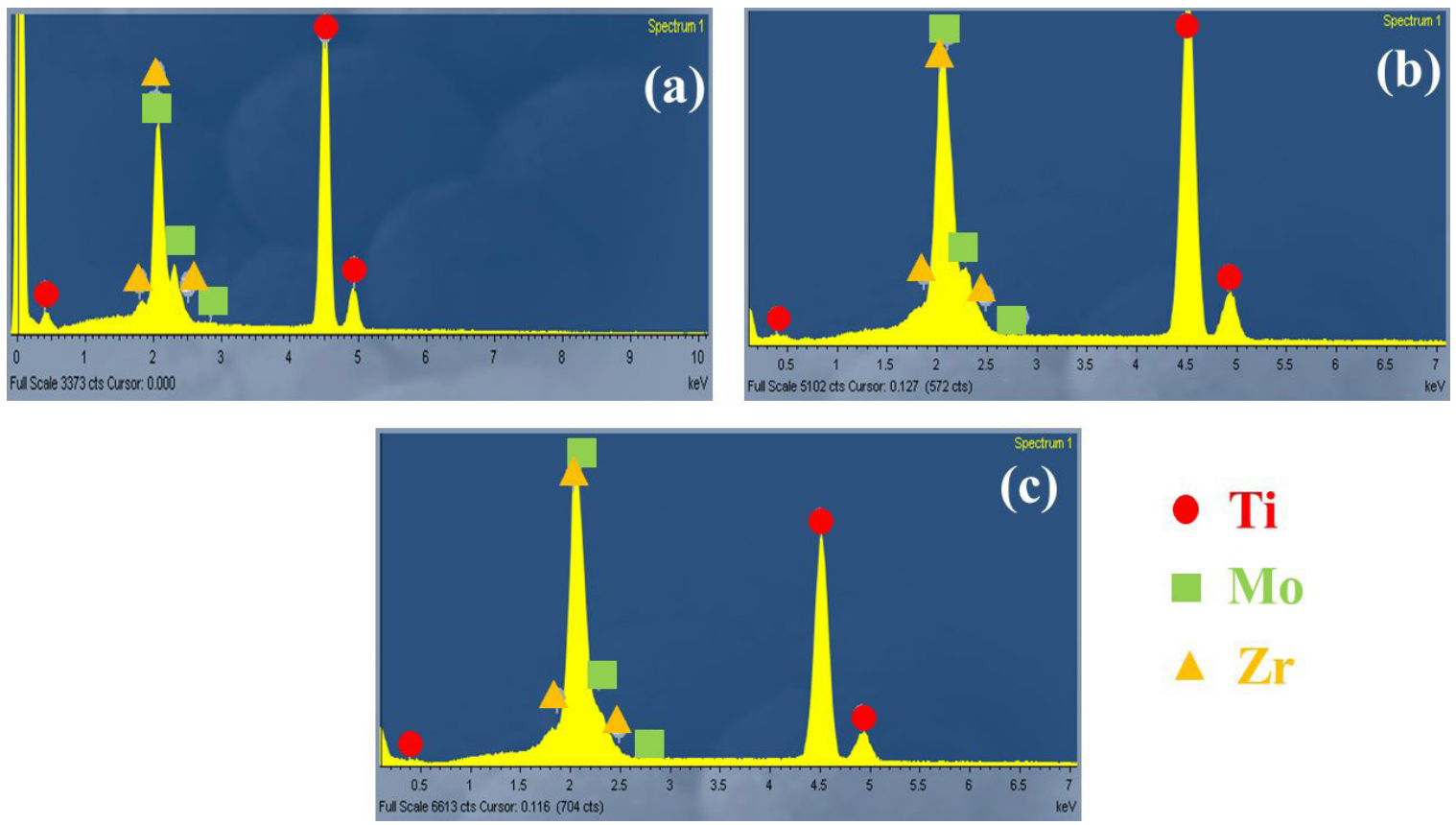

Ti
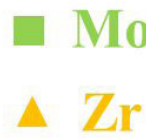

Figure 1. EDS spectra for Ti-10Mo-30Zr (a), Ti-10Mo-40Zr (b) and Ti-10Mo-50Zr (c) alloys. 

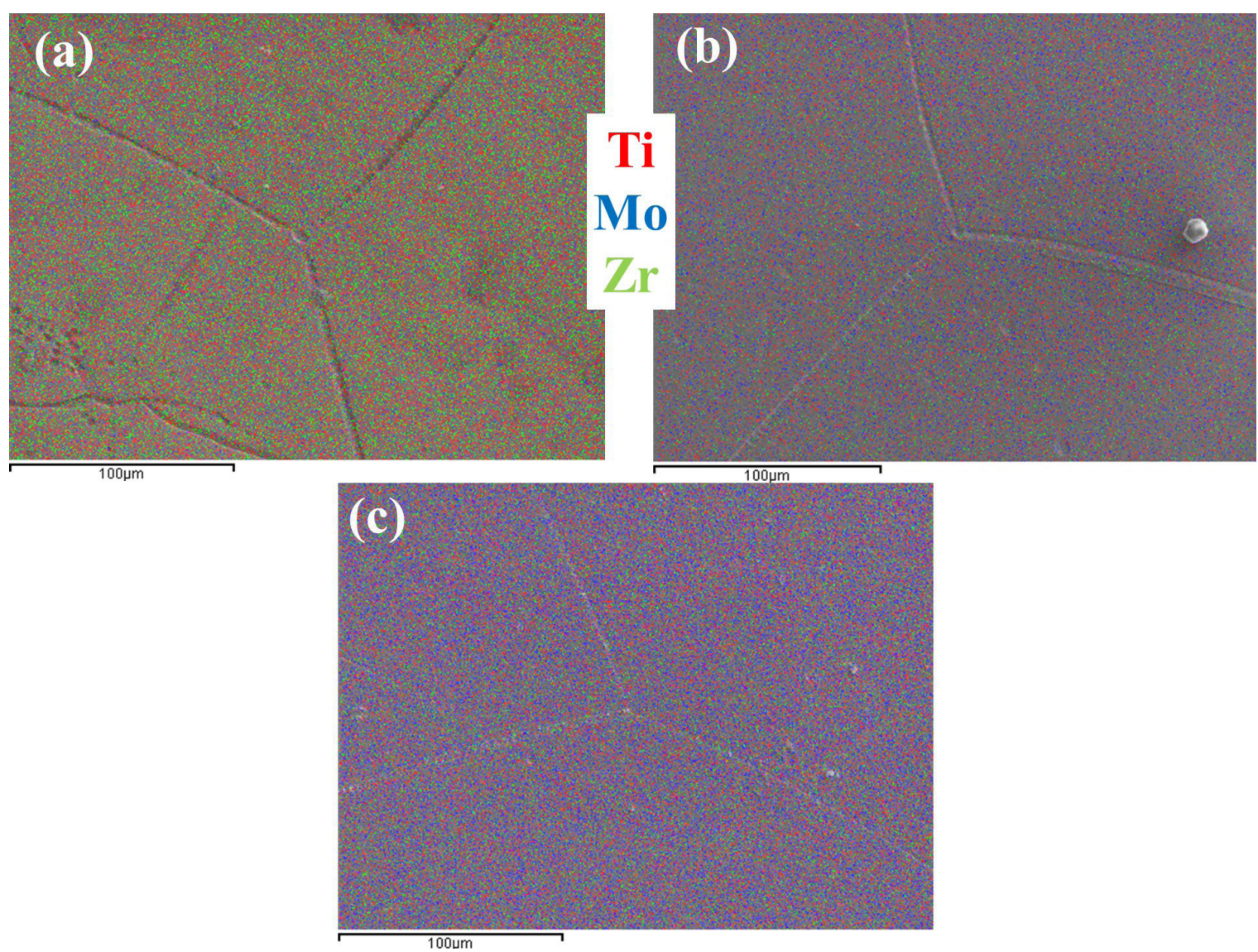

Figure 2. EDS elements mapping of the Ti-10Mo-30Zr (a), Ti-10Mo-40Zr (b), and Ti-10Mo-50Zr (c) alloys.

Table 1. Chemical composition of the Ti-10Mo-Zr produced alloys, obtained by EDS.

\begin{tabular}{cccc}
\hline $\begin{array}{c}\text { Element } \\
(\mathrm{wt} \%)\end{array}$ & Ti-10Mo-30Zr & Ti-10Mo-40Zr & Ti-10Mo-50Zr \\
\hline $\mathrm{Mo}$ & 9.20 & 9.95 & 9.57 \\
\hline $\mathrm{Zr}$ & 30.5 & 39.11 & 49.28 \\
\hline $\mathrm{Ti}$ & Balance & Balance & Balance \\
\hline
\end{tabular}

of the nominal concentration. The alloys of this study are within the established interval, validating the results of the chemical analysis.

In Figure 2, it can be shown the mapping of the compositions made by EDS, in which the red, blue, and green colors represent titanium, molybdenum, and zirconium, respectively. A good distribution of the elements, without precipitates or aggregates, was observed in all samples, indicating good homogeneity.

Regarding density, experimentally and theoretically obtained data are presented in Figure 3. Density is one of the important physical properties to study in biomedical materials, as specific strength is one of the criteria for biocompatibility ${ }^{35}$. In the medical industry, low-density values are better, as they reduce the extra weight load on the organs around the implant, avoiding material stress ${ }^{36}$.

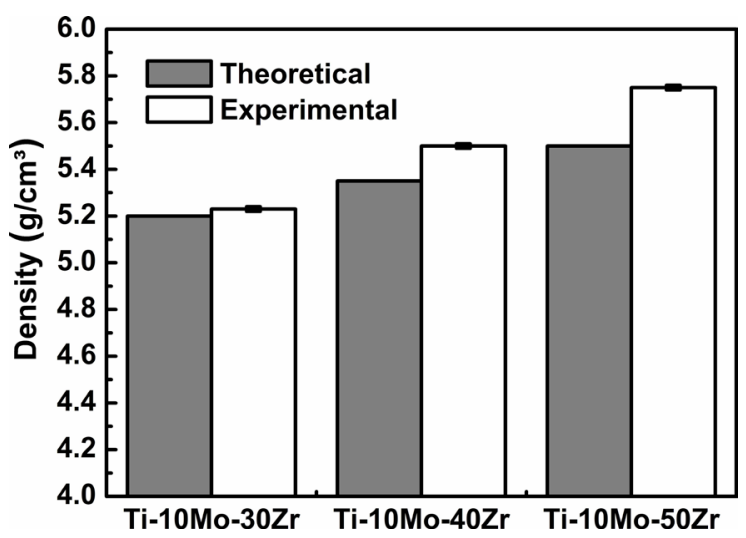

Figure 3. Density of the produced Ti-10Mo-Zr alloys.

The alloys in the Ti-Mo-Zr system stand out from the Ti-6Al-V $\left(4.41 \mathrm{~g} / \mathrm{cm}^{3}\right), \mathrm{Cp}-\mathrm{Ti}\left(4.54 \mathrm{~g} / \mathrm{cm}^{3}\right)$, and Ti-15Mo $\left(5.01 \mathrm{~g} / \mathrm{cm}^{3}\right)$ because they have high-density values. This fact is due to the addition of the elements $\operatorname{Zr}\left(6.51 \mathrm{~g} / \mathrm{cm}^{3}\right)$ and $\mathrm{Mo}\left(10.22 \mathrm{~g} / \mathrm{cm}^{3}\right)$ because, when added as alloying elements, they increase their density ${ }^{37}$. Even with high values, the densities of the alloys presented in this paper are lower when compared to others used in the orthopedics field, such as stainless steel $\left(7.5 \mathrm{~g} / \mathrm{cm}^{3}\right.$ and cobalt-based alloys $\left(8,3 \mathrm{~g} / \mathrm{cm}^{3}\right)^{13,36}$. When the 


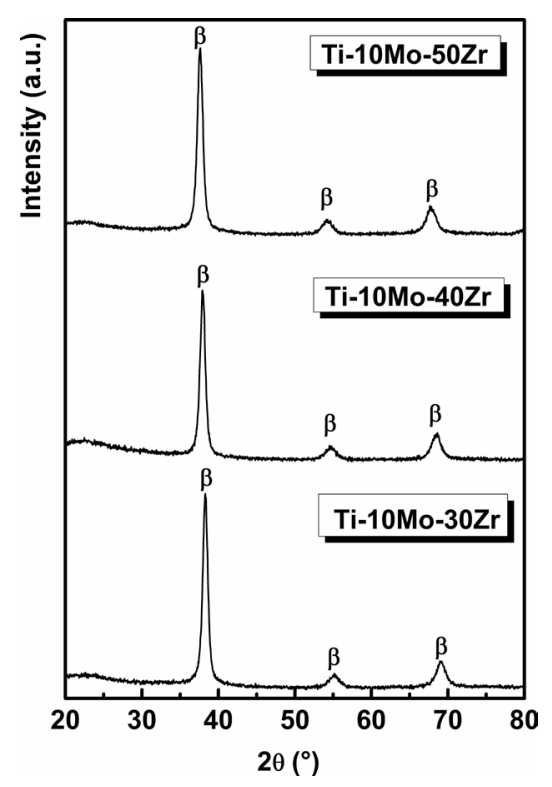

Figure 4. X-ray diffractograms for samples of as-cast Ti-10Mo-Zr alloys.
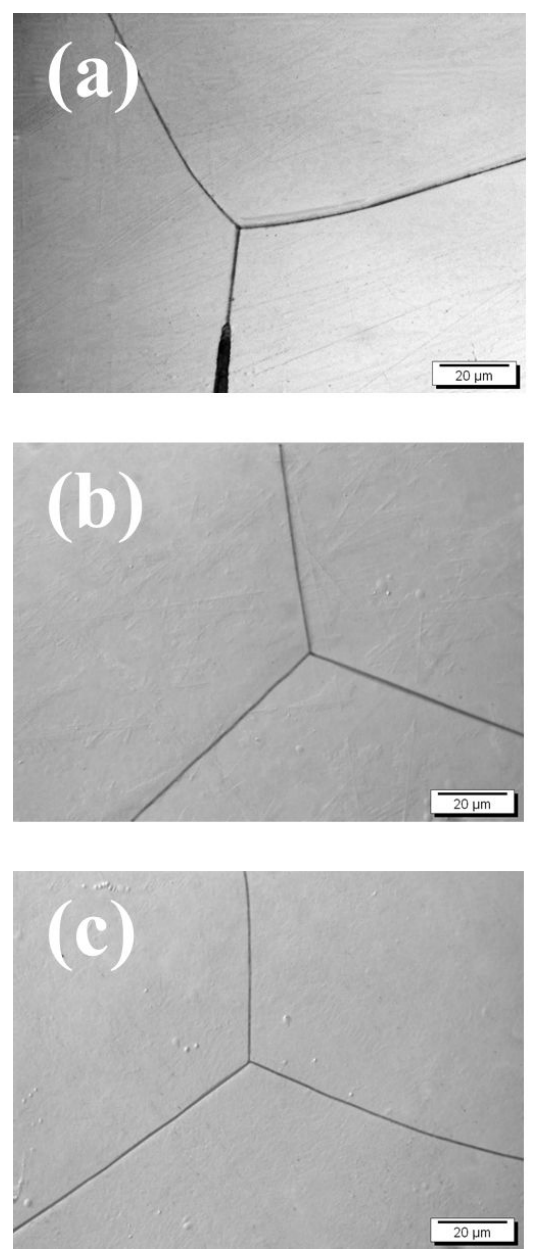

theoretical value is compared with the experimental value, an increase can be seen, which can be attributed to metallic impurities ( $\mathrm{Al}, \mathrm{Cr}, \mathrm{Fe}, \mathrm{Mn}$, and $\mathrm{Ni}$ ) and also to interstitial elements $(\mathrm{O}, \mathrm{C} \mathrm{N} \text {, and } \mathrm{H})^{38}$.

Figure 4 shows the spectra obtained by $X$-ray diffraction for Ti-10Mo-30Zr, Ti-10Mo-40Zr, and Ti-10Mo-50Zr alloys. It can be observed only peaks related to the $\beta$ phase. Ho et al. ${ }^{28}$ studied Ti-Mo alloys and observed the beta stabilizing effect of molybdenum above $10 \%$ in weight as an alloying element. Zirconium is a neutral element, but when added as an alloying element together with another or more beta stabilizing elements, it can act as a beta stabilizing agent and help, therefore, in the consolidation of this phase ${ }^{13}$.

Figure 5 shows the micrographs obtained by optical and scanning electron microscope for the Ti-10Mo-Zr alloys.

According to Ho et al. ${ }^{39}$, a characteristic morphological predominance of the $\beta$ phase is observed by analyzing the obtained micrographs. These authors verified that with almost $10 \mathrm{wt} \%$ of molybdenum, only the beta phase's presence occurs. On the other hand, zirconium acted as a neutral element, maintaining the beta phase without other phases during the analysis as the proportions increased.
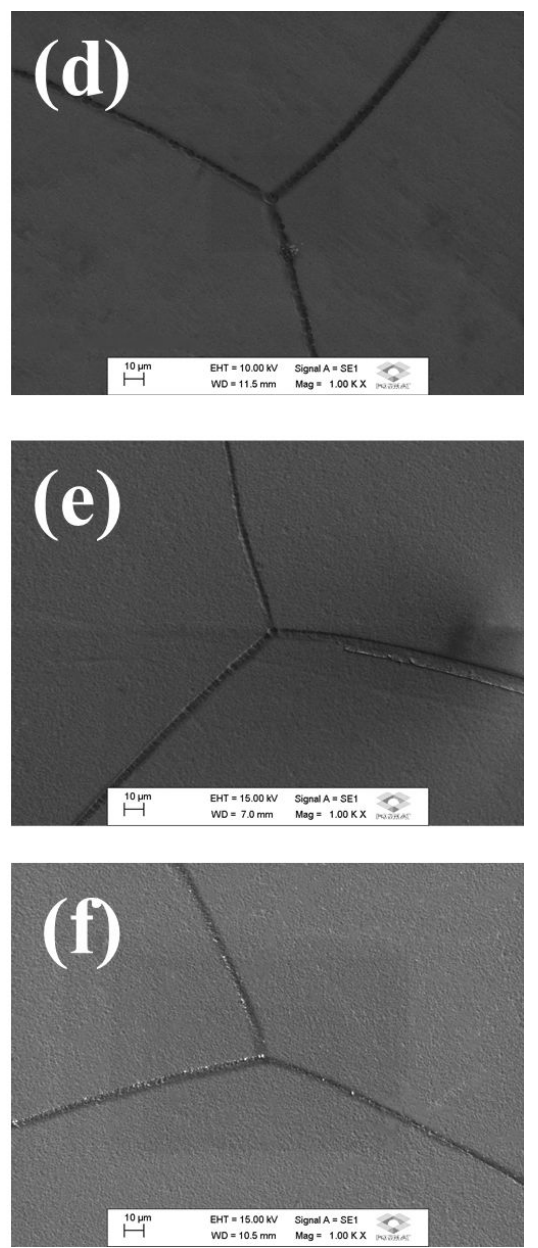

Figure 5. Optical micrographs for Ti-10Mo-30Zr (a), Ti-10Mo-40Zr (b) and Ti-10Mo-50Zr (c) alloys; scanning electron micrographs Ti-10Mo-30Zr (d), Ti-10Mo-40Zr (e) and Ti-10Mo-50Zr (f) alloys. 


\section{Conclusions}

From the obtained results, it is possible to conclude that the as-cast Ti-10Mo-Zr alloys have an intense beta phase by the X-ray diffraction and microscopy measurements. These preliminary results make it possible to conclude that the produced alloys can be applied as a biomaterial, completing the study with some mechanical tests (as hardness and elasticity modulus) and biocompatibility tests.

\section{Acknowledgments}

The authors would like to thank Professor Oscar Balancin and Rover Belo (UFSCar) for using hot-rolling equipment. This study was financed in part by the Coordenação de Aperfeiçoamento de Pessoal de Nível Superior - Brasil (CAPES) - Finance Code 001 and CNPq (grants \#308.204/2017-4 and \#148.171/2019-2).

\section{References}

1. Kaur M, Singh K. Review on titanium and titanium based alloys as biomaterials for orthopaedic applications. Mater Sci Eng C. 2019;102:844-62.

2. Kaur M, Singh K. Review on titanium and titanium based alloys as biomaterials for orthopaedic applications. Mater Sci Eng C. 2019;102:844-62.

3. Geetha M, Singh AK, Asokamani R, Gogia AK. Ti based biomaterials, the ultimate choice for orthopaedic implants: a review. Prog Mater Sci. 2009;54(3):397-425.

4. Nicholson J. Titanium alloys for dental implants: a review. Prosthesis. 2020;2(2):100-16.

5. Vizureanu P, Bălțatu MS. Titanium-based alloys for biomedical applications. Millersville, PA: Materials Research Forum LLC; 2020. 160 p.

6. Noumbissi S, Scarano A, Gupta S. A literature review study on atomic ions dissolution of titanium and its alloys in implant dentistry. Materials. 2019;12(3):368.

7. Mello DCR, de Oliveira JR, Cairo CAA, Ramos LSB, Vegian MRC, de Vasconcellos LGO, et al. Titanium alloys: in vitro biological analyzes on biofilm formation, biocompatibility, cell differentiation to induce bone formation, and immunological response. J Mater Sci Mater Med. 2019;30(9):108.

8. Çallığlu Ş, Acar P. Design of $\beta$-Titanium microstructures for implant materials. Mater Sci Eng C. 2020;110:110715.

9. Chen L-Y, Cui Y-W, Zhang L-C. Recent development in beta titanium alloys for biomedical applications. Metals. 2020;10(9):1139.

10. Martins JRS Jr, Grandini CR. Structural characterization of Ti-15Mo alloy used as biomaterial by Rietveld method. J Appl Phys. 2012;111(8):083535-8.

11. Martins JRS Jr, Nogueira RA, Araújo RO, Donato TAG, Arana-Chavez VE, Claro APRA, et al. Preparation and characterization of Ti-15Mo alloy used as biomaterial. Mater Res. 2011;14(1):107-12.

12. Correa DRN, Kuroda PAB, Lourenco ML, Fernandes CJC, Buzalaf MAR, Zambuzzi WF, et al. Development of Ti-15ZrMo alloys for applying as implantable biomedical devices. J Alloys Compd. 2018;749:163-71.

13. Correa DRN, Vicente FB, Araújo RO, Lourenço ML, Kuroda PAB, Buzalaf MAR, et al. Effect of the substitutional elements on the microstructure of the Ti-15Mo-Zr and Ti-15Zr-Mo systems alloys. J Mater Res Technol. 2015;4(2):180-5.

14. Correa DRN, Vicente FB, Donato TAG, Arana-Chavez VE, Buzalaf MAR, Grandini CR. The effect of the solute on the structure, selected mechanical properties, and biocompatibility of Ti-Zr system alloys for dental applications. Mater Sci Eng C. 2014;34:354-9.
15. Vicente FB, Correa DRN, Donato TAG, Arana-Chavez VE, Buzalaf MAR, Grandini CR. The Influence of small quantities of oxygen in the structure, microstructure, hardness, elasticity modulus and cytocompatibility of Ti-Zr Alloys for dental applications. Materials. 2014;7(1):542-53.

16. Kuroda PAB, Freitas Quadros F, Sousa KSJ, Donato TAG, de Araújo RO, Grandini CR. Preparation, structural, microstructural, mechanical and cytotoxic characterization of as-cast Ti-25Ta-Zr alloys. J Mater Sci Mater Med. 2020;31(2):19.

17. Quadros FF, Kuroda PAB, Sousa KSJ, Donato TAG, Grandini CR. Preparation, structural and microstructural characterization of Ti-25Ta-10Zr alloy for biomedical applications. J Mater Res Technol. 2019;8(5):4108-14.

18. Çaha I, Alves AC, Kuroda PAB, Grandini CR, Pinto AMP, Rocha $\mathrm{LA}$, et al. Degradation behavior of Ti-Nb alloys: corrosion behavior through 21 days of immersion and tribocorrosion behavior against alumina. Corros Sci. 2020;167:108488. http:// dx.doi.org/10.1016/j.corsci.2020.108488.

19. Kuroda PAB, Silva LM, Sousa KSJ, Donato TAG, Grandini CR. Preparation, structural, microstructural, mechanical, and cytotoxic characterization of Ti-15Nb alloy for biomedical applications. Artif Organs. 2020;44(8):811-7.

20. Pereira BL, Lepienski CM, Seba V, Hobold G, Soares P, Chee BS, et al. Titanium-niobium (Ti-xNb) alloys with high $\mathrm{Nb}$ amounts for applications in biomaterials. Mater Res. 2020;23(6):e20200405.

21. Martins JRS Jr, Matos AA, Oliveira RC, Buzalaf MAR, Costa I, Rocha LA, et al. Preparation and characterization of alloys of the Ti-15Mo-Nb system for biomedical applications. J Biomed Mater Res B Appl Biomater. 2018;106(2):639-48.

22. Kolli R, Devaraj A. A review of metastable beta titanium alloys. Metals. 2018;8(7):506.

23. Collings EW. The physical metallurgy of titanium alloys. Ohio: ASM International; 1989.

24. Lütjering G, Williams JC, Gysler A. Microstructure and mechanical properties of titanium alloys. In: Li JCM, editor. Microstructure and properties of materials. New Jersey: World Scientific; 1998. p. 1-77.

25. Terpiłowska S, Siwicka-Gieroba D, Siwicki AK. Cytotoxicity of Iron (III), Molybdenum (III), and their Mixtures in BALB/3T3 and HepG2 Cells. J Vet Res. 2018;62(4):527-33. http://dx.doi. org/10.2478/jvetres-2018-0066.

26. Myslyvchenko OM, Bondar AA, Horban VF, Luhovskyi YF, Sobolev VB, Tikhonova IB. Structure and physicomechanical properties of cast titanium alloys of the $\mathrm{Ti}-\mathrm{Nb}-\mathrm{Mo}$ system. Mater Sci. 2020;56(2):224-31.

27. Kuroda PAB, Buzalaf MAR, Grandini CR. Effect of molybdenum on structure, microstructure and mechanical properties of biomedical Ti-20Zr-Mo alloys. Mater Sci Eng C. 2016;67:511-5.

28. Ho WF, Ju CP, Chern Lin JH. Structure and properties of cast binary Ti-Mo alloys. Biomaterials. 1999;20(22):2115-22.

29. Bania PJ. Beta titanium alloys and their role in the titanium industry. In: Eylon D, Boyer RR, Koss DA, editors. Titanium alloys in the 1990's. Warrendale: The Mineral, Metals \& Materials Society; 1993.

30. Davis JR. Metals handbook desk edition. 2nd ed. Materials Park: ASM International; 1998. Zirconium and Hafnium.

31. Cordeiro JM, Beline T, Ribeiro ALR, Rangel EC, Cruz NC, Landers R, et al. Development of binary and ternary titanium alloys for dental implants. Dent Mater. 2017;33(11):1244-57.

32. Cordeiro JM, Faverani LP, Grandini CR, Rangel EC, Cruz NC, Nociti FH Jr, et al. Characterization of chemically treated Ti-Zr system alloys for dental implant application. Mater Sci Eng C. 2018;92:849-61.

33. Ho W-F, Chen W-K, Wu S-C, Hsu H-C. Structure, mechanical properties, and grindability of dental $\mathrm{Ti}-\mathrm{Zr}$ alloys. J Mater Sci Mater Med. 2008;19(10):3179-86.

34. American Society for Testing and Materials - ASTM. ASTM F2066-08: standard specification for wrought titanium-15 
molybdenum alloy for surgical implant application. Philadelphia: ASTM International; 2008.

35. Kim T-I, Han J-H, Lee I-S, Lee K-H, Shin M-C, Choi B-B. New titanium alloys for biomaterials: a study of mechanical and corrosion properties and cytotoxicity. Biomed Mater Eng. 1997;7(4):253-63.

36. Araújo RO, Buzalaf MAR, Grandini CR. Preparation and characterization of Ti-10Mo-xZr alloys for biomedical applications. Mater Sci Forum. 2016;869:940-5.
37. Lide D. CRC handbook of chemistry and physics: a readyreference book of chemical and physical data. 85th ed. Boca Raton: CRC Press; 2004. 2712 p.

38. Polmear I, StJohn D, Nie J-F, Qian M. 7 - Titanium alloys. In: Polmear I, StJohn D, Nie J-F, Qian M, editors. Light alloys. 5th ed. Boston: Butterworth-Heinemann; 2017. p. 369-460.

39. Ho W-F, Wu S-C, Hsu S-K, Li Y-C, Hsu H-C. Effects of molybdenum content on the structure and mechanical properties of as-cast Ti-10Zr-based alloys for biomedical applications. Mater Sci Eng C. 2012;32(3):517-22. 